\title{
PENGARUH KREDIBILITAS INFLUENCER DI MEDIA SOSIAL TERHADAP KEPUTUSAN WISATAWAN MILENIAL KE LABUAN BAJO
}

\author{
Michael Reivin Limengka ${ }^{1}$, N.M.S. Wijaya ${ }^{2}$, Putu Agus Wikanatha Sagita ${ }^{3}$ \\ Email: reivin_limengka@yahoo.com ${ }^{1}$, sofia_ipw@unud.ac.id ${ }^{2}$, aguswika@unud.ac.id ${ }^{3}$ \\ 1,2,3Program Studi Sarjana Industri Perjalanan Wisata, Fakultas Pariwisata, Universitas Udayana
}

\begin{abstract}
The study aims at finding out the characteristic of the millennial tourists who visit Labuan Bajo and identifying the influence of the social media influencers' credibility on their decision to visit Labuan Bajo. In selecting the sample, the study used the purposive sampling method in which some online questionnaires were given to 100 respondents via Google Form feature. The techniques of analyzing the data applied in the study were descriptive qualitative and multiple linear regression analysis using IBM SPSS 25.0 for Windows application. The result of the study shows that, partially and simultaneously, there is a positive impact of the social media influencers' credibility on the millennial tourists' decision to visit Labuan Bajo. The results showed that partially, the influencers' credibility positively and significantly affected the millennial tourists' decision to visit Labuan Bajo. The sig. value of each are as follows: Attractiveness (X1) of $0.043<0.05$; The Trustworthiness (X2) of $0.047<0.05$ and the Expertise $(\mathrm{X} 3)$ of $0.000<0.05$. While simultaneously, there is a positively and significantly affected the social media Influencers' credibility on the Millennial tourists's decision to visit Labuan Bajo, with a sig. value of $0.000<0.05$.
\end{abstract}

\begin{abstract}
Abstrak: Penelitian ini dilakukan untuk mengetahui karakteristik wisatawan milenial yang berkunjung ke Labuan Bajo dan untuk mengetahui pengaruh dimensi kredibilitas influencer di media sosial terhadap keputusan wisatawan milenial berkunjung ke Labuan Bajo. Dalam menentukan sampel, peneliti menggunakan metode purposive sampling yang dimana peneliti memberikan kuesioner secara online (daring) melalui google form kepada 100 orang responden. Teknik analisis data yang digunakan adalah teknik analisis data deskriptif kuantitatif dan analisis regresi linear berganda menggunakan aplikasi IBM SPSS 25.0 for Windows. Hasil penelitian menunjukkan bahwa secara parsial dimensi kredibilitas influencer berpengaruh secara positif dan signifikan terhadap keputusan wisatawan milenial berkunjung ke Labuan Bajo. Adapun nilai signifikan masing-masing adalah sebagai berikut: Daya Tarik (X1) sebesar $0.043<0.05$; Kepercayaan (X2) sebesar $0.047<0.05$ dan Keahlian (X3) sebesar $0.000<$ 0.05. Sedangkan secara simultan, terdapat pengaruh positif dan siginifikan antara dimensi kredibilitas Influencer di media sosial terhadap keputusan wisatawan milenial berkunjung ke Labuan Bajo, dengan nilai signifikan sebesar $0.000<0.05$.
\end{abstract}

Keywords: credibility's influencer, social media, decision TO visit, millennial tourist.

\section{PENDAHULUAN}

Memasuki era teknologi yang maju ini, segala hal berubah menjadi lebih cepat dan praktis serta efisien, hal ini dikarenakan hadirnya internet yang banyak membantu kehidupan manusia. Internet juga membawa pengaruh yang besar dalam kepariwisataan, internet banyak memberikan manfaat untuk mempermudah jalannya roda kepariwisataan, misalnya seperti menjadikan pemesanan tiket transportasi menjadi lebih efisien dan praktis, karena wisatawan yang ingin berwisata dapat memesan tiket melalui online yang terhubung dengan jaringan internet, selain itu melalui internet wisatawan juga dapat mengakses informasi mengenai perjalanan dengan mudah di berbagai platform yang ada. Hasil studi dari Asosiasi Penyelenggara Jasa Internet Indonesia (APJII) mengenai internet, pada 2018 jumlah pengguna internet di Indonesia menyentuh angka 171,17 juta jiwa. Angka ini setara dengan $64,8 \%$ total penduduk Indonesia 264,16 juta jiwa (www.cnbcindonesia.com, 2020). Salah 
satu platform yang menggunakan internet dalam berkomunikasi adalah media sosial.

Media sosial dipandang sebagai alat komunikasi yang efektif dan praktis dalam berkomunikasi di era saat ini. Masyarakat banyak mengakses media sosial dalam melakukan kegiatan sehari-harinya, selain digunakan untuk berkomunikasi antara satu dengan lainnya, media sosial juga digunakan dalam mencari hiburan atau entertainment, melalui media sosial masyarakat banyak menemukan hal-hal yang dianggap menarik dan menghibur. Salah satu media sosial yang populer adalah Instagram. Semakin berkembangnya Instagram di Indonesia, maka semakin beragam pula karakter penggunanya (Hanifah, 2019). Hal ini dapat diamati dari akun apa saja yang diikuti oleh pengguna di Instagram.

Generasi milenial umumnya dikenal dengan generasi $\mathrm{Y}$, mendominasi penggunaan media sosial. Generasi milenial ini bisa dikatakan sebagai generasi yang sudah terbiasa dengan teknologi, karena selalu menggunakan teknologi yang maju. Generasi ini menjadi salah satu target atau konsumen untuk pangsa pasar digital marketing. Dalam menjangkau pasar yang sesuai dengan target dalam melakukan digital marketing, perusahaan akan mengupayakan hal-hal dalam membangun kesan yang baik dan positif mengenai produk yang dijual. Salah satu cara yang seringkali digunakan oleh perusahaan dalam melakukan pemasaran melalui media digital adalah dengan bekerja sama dengan para influencer. Influencer merupakan figur di media sosial dengan jumlah pengikut yang banyak, dan apa yang mereka sampaikan dapat mempengaruhi perilaku dari pengikutnya. (Hariyanti \& Wirapraja, 2018: 141). Influencer digemari atau disukai oleh audiens mereka, sehingga apa yang mereka pakai atau lakukan akan menjadi sorotan karena dianggap dapat menginspirasi dan mempengaruhi pengikutnya. Influencer ini selanjutnya akan berperan untuk mempengaruhi keputusan lingkungan terdekatnya untuk dapat mengenal sebuah produk yang telah dipromosikan melalui media sosial berupa konten yang telah dibuat, baik itu foto, video, ulasan dan lain-lain. Salah satu aspek yang menggunakan influencer sebagai digital marketing adalah dalam kepariwisataan.

Wisatawan yang melakukan aktivitas wisata mengunjungi suatu daya tarik wisata tertentu, tentu saja mempunyai berbagai pertimbangan dalam melakukan keputusan berkunjungnya contohnya seperti wisatawan milenial, wisatawan milenial saat ini merupakan wisatawan dengan tren yang cukup berkembang belakangan ini. Wisatawan milenial mencari informasi sebelum melakukan perjalanan menuju ke suatu destinasi wisata di media sosial, salah satunya seperti sebelum berkunjung ke destinasi Labuan Bajo.

Labuan Bajo termasuk sebagai tujuan destinasi wisata populer di Indonesia, Labuan Bajo sendiri terletak di kecamatan Komodo, kabupaten Manggarai Barat, Provinsi Nusa Tenggara Timur. Data kunjungan wisatawan ke Labuan Bajo pada tahun 2015 sampai dengan 2017 mengalami penurunan dan kenaikan pada tahun 2018 secara signifikan, hal ini disebabkan karena berkembangnya program 10 Bali Baru yang dikeluarkan oleh Menteri Pariwisata periode sebelumnya yaitu, Arief Yahya, kebijakan tentang 10 destinasi wisata atau yang disebut 'Bali Baru' berkembang pada akhir tahun 2017. Ada 4 (empat) destinasi yang dijadikan sebagai destinasi prioritas dari sepuluh (10) destinasi yang ada, Labuan Bajo adalah salah satunya. (travel.kompas.com, 2017).

Berbagai hal dipersiapkan, seperti membangun infrastruktur dan fasilitas-fasilitas untuk menunjang kenyamanan wisatawan yang akan berkunjung. Promosi juga dilakukan untuk memperkenalkan destinasi Labuan Bajo oleh Menteri Pariwisata dan Ekonomi Kreatif dengan melibatkan influencer. Positif dari Influencer sangat berpengaruh terhadap penjualan sebuah produk dikarenakan tingkat kepercayaan pengguna terhadap kredibilitas Influencer.

Kredibilitas influencer sangat penting untuk audience dapat menerima informasi yang diberikan oleh influencer sebagai sumber informasi kepada pengikut atau audience sebagai komunikan. Menurut Ohanian (1990), kredibilitas influencer memiliki beberapa dimensi, antara lain meliputi daya tarik, kepercayaan dan keahlian. Daya tarik mencakup mengenai kesamaan, penampilan dan menarik atau tidaknya seorang influencer. Pada aspek kepercayaan, mencakup mengenai kejujuran, ketulusan dan dapat dipercaya atau tidaknya influencer dalam menyampaikan suatu hal. Sedangkan pada aspek keahlian, mencakup mengenai pengetahuan, pengalaman dan keahlian seorang influencer. Glover (2009) merangkum manfaat dari dukungan selebriti salah satunya sebagai yang berkaitan dengan menarik perhatian audience, lebih jauh Glover 
menekankan pentingnya mereka untuk pemasaran pariwisata, menunjukkan bahwa citra destinasi dan kesadaran dapat dipengaruhi secara signifikan melalui dukungan mereka, oleh sebab itu, influencer sangat penting bagi promosi kepariwisataan, melalui influencer, informasi mengenai produk pariwisata dapat dengan mudah sampai kepada konsumen. Berdasarkan fenomena-fenomena tersebut, peneliti merasa penting untuk mengadakan penelitian untuk mengetahui bagaimana pengaruh yang ditimbulkan oleh influencer, yang berjudul "pengaruh kredibilitas influencer di media sosial terhadap keputusan berkunjung wisatawan milenial ke Labuan Bajo".

\section{METODE PENELITIAN}

Penelitian ini menggunakan penyebaran kuesioner secara online dengan menggunakan google form sebagai alat dalam menyebarkan kuesioner. Adapun kuesioner dibagikan kepada pengikut (followers) dari influencer yang digunakan dalam penelitian ini. Followers atau audiens dari influencer yang telah melakukan kunjungan wisata ke Labuan Bajo, setelah influencer memposting konten di media sosial Instagram. Selain itu, kerabat, teman dan keluarga penulis yang sudah pernah berkunjung ke Labuan Bajo juga menjadi sampel pada penelitian ini diberikan tautan yang dapat terhubung langsung ke kuesioner online tersebut.

Teknik pengumpulan data dilakukan dengan teknik observasi melalui akun instagram influencer, studi pustaka dan penyebaran kuesioner. Teknik pengambilan sampel menggunakan purposive sampling, yaitu dengan syarat tertentu. Wisatawan milenial dengan usia berada pada rentang 20 sampai 40 tahun, mengikuti akun atau menjadi pengikut dari influencer tersebut, dan melakukan kunjungan ke Labuan Bajo. Sampel yang dimaksud dalam penelitian ini merupakan wisatawan milenial yang mengikuti salah satu akun dari influencer dan melakukan kunjungan setelah influencer mengunggah konten wisata mengenai Labuan Bajo. Metode pengambilan sampel dalam penelitian ini menggunakan rumus Slovin.

\section{HASIL DAN PEMBAHASAN}

\section{Gambaran Umum Kabupaten Manggarai Barat dan Labuan Bajo.}

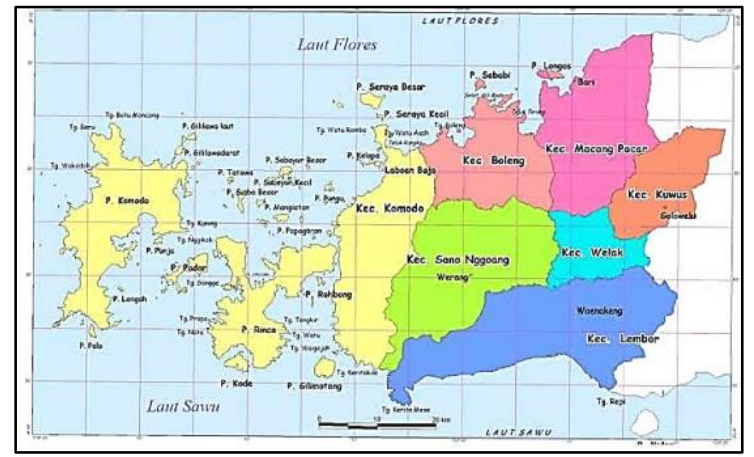

Gambar 1. Peta Kabupaten Manggarai Barat.

Sumber: google.com/maps, 2020

Kabupaten Manggarai Barat merupakan hasil pemekaran wilayah administratif Kabupaten Manggarai, melalui UU RI NO. 8 Tahun 2003. Kabupaten Manggarai Barat terletak pada bagian paling barat pulau Flores di Propinsi Nusa Tenggara Timur, Indonesia. Kabupaten ini memiliki 12 Kecamatan yang terdiri atas Kecamatan Sano Nggoang, Mbeliling, Pacar, Boleng, Kuwus, Lembor, Lembor Selatan, Welak, Ndoso, Komodo, Macang Pacar, dan Kecamatan Kuwus Barat. Selain 12 kecamatan ini, Manggarai Barat juga memiliki beberapa pulau kecil seperti Pulau Komodo, Pulau Seraya Besar, Pulau Rinca, Pulau Seraya Kecil, Pulau Bidadari dan Pulau Longos.

Labuan Bajo merupakan ibu kota dari kabupaten Manggarai Barat, dimana destinasi ini termasuk dari 10 destinasi Bali Baru yang dikembangkan oleh pemerintah, destinasi wisata ini menyimpan berbagai keindahan alam yang luar biasa. Berikut ini merupakan data kunjungan wisatawan ke Labuan Bajo.

Tabel 1. Data Pertumbuhan Wisatawan ke Labuan Bajo Tahun 2015 - 2018

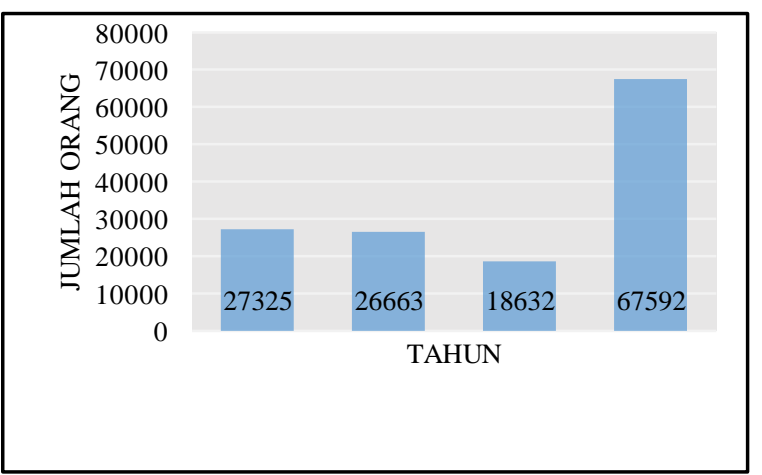

Sumber: Data BPSS Manggarai Barat, 2019 
Berdasarkan data di atas, diketahui bahwa jumlah kunjungan wisatawan ke Labuan Bajo pada tahun 2015 berjumlah 27.325 orang dan mengalami penurunan sebesar $2,42 \%$ pada tahun 2016. Selanjutnya, jumlah kunjungan wisatawan kembali menurun pada tahun 2017 sebesar 30, $12 \%$. Namun, pada tahun 2018, jumlah kunjungan wisatawan meningkat secara signifikan sebesar $72,43 \%$.

\section{Karakteristik Wisatawan Milenial Yang Berkunjung Ke Labuan Bajo.}

Karakteristik wisatawan milenial dibagi menjadi beberapa karakteristik, yaitu berdasarkan usia, jenis kelamin, status pernikahan, daerah asal, pendidikan, profesi, pendapatan per bulan, akomodasi, tujuan berkunjung dan frekuensi kunjungan. Berdasarkan 100 sampel yang telah dibagikan kepada 100 wisatawan milenial yang ke Labuan Bajo, didapati karakteristik berdasarkan usia, generasi milenial awal dengan rentang usia $20-$ 29 tahun merupakan yang terbanyak sebesar $87 \%$, jenis kelamin perempuan mendominasi sebesar $63 \%$. Berdasarkan status pernikahan yaitu belum menikah sebesar $87 \%$. Berdasarkan daerah asal wisatawan sebesar $35 \%$ berasal dari provinsi Bali. Berdasarkan status pendidikan, didapati dengan tingkat pendidikan Sarjana sebesar 54\%. Berdasarkan profesi, didapati mahasiswa sebesar $35 \%$. Dilihat dari pendapatan per bulan, ditemukan pendapatan sebesar Rp. 2.500.000 - Rp.5.000.000 mendominasi sebesar $61 \%$. Berdasarkan akomodasi yang digunakan, didapati akomodasi hotel yang paling tertinggi sebesar $46 \%$. Berdasarkan tujuan berkunjung, didapati berlibur sebesar 92\%. Berdasarkan frekuensi kunjungan, dengan kunjungan pertama kali sebesar $77 \%$.

\section{Frekuensi Responden Terhadap Kredibilitas Influencer}

Berikut ini merupakan tabel frekuensi
persepsi responden terhadap dimensi
kredibilitas influencer.

Tabel 2. Frekuensi Kredibilitas Influencer

\begin{tabular}{|c|c|c|c|c|c|c|c|}
\hline \multirow{2}{*}{ No } & \multirow{2}{*}{ Pernyataan } & \multicolumn{4}{|c|}{ Frekuensi Penilaian } & \multirow{2}{*}{$\begin{array}{c}\text { Rata- } \\
\text { rata }\end{array}$} & \multirow{2}{*}{ Kategori } \\
\hline & & STS & TS & $\mathrm{S}$ & SS & & \\
\hline 1 & $\begin{array}{l}\text { Konten } \\
\text { Menarik } \\
\text { (X1.1) }\end{array}$ & - & 1 & 39 & 60 & 3.59 & $\begin{array}{l}\text { Sangat } \\
\text { Setuju }\end{array}$ \\
\hline 2 & $\begin{array}{l}\text { Minat yang } \\
\text { sama (X1.2) }\end{array}$ & - & 4 & 35 & 61 & 3.57 & $\begin{array}{l}\text { Sangat } \\
\text { Setuju }\end{array}$ \\
\hline
\end{tabular}

\begin{tabular}{clcccccc}
\hline 3 & $\begin{array}{l}\text { Penampilan } \\
(X 1.3)\end{array}$ & - & 5 & 55 & 40 & 3.35 & $\begin{array}{l}\text { Sangat } \\
\text { Setuju }\end{array}$ \\
\hline 4 & $\begin{array}{l}\text { Informasi } \\
\text { Akurat } \\
(X 2.1)\end{array}$ & - & 1 & 54 & 45 & 3.44 & $\begin{array}{l}\text { Sangat } \\
\text { Setuju }\end{array}$ \\
\hline 5 & $\begin{array}{l}\text { Penilaian } \\
\text { Objektif } \\
(X 2.2)\end{array}$ & - & 1 & 66 & 33 & 3.32 & $\begin{array}{l}\text { Sangat } \\
\text { Setuju }\end{array}$ \\
\hline 6 & $\begin{array}{l}\text { Komunikasi } \\
\text { Jujur (X2.3) }\end{array}$ & - & 12 & 52 & 36 & 3.23 & Setuju \\
\hline 7 & $\begin{array}{l}\text { Pengetahuan } \\
(X 3.1)\end{array}$ & - & 8 & 58 & 34 & 3.24 & $\begin{array}{l}\text { Sangat } \\
\text { Setuju }\end{array}$ \\
\hline 8 & $\begin{array}{l}\text { Pengalaman } \\
(X 3.2)\end{array}$ & - & 9 & 57 & 34 & 3.25 & Setuju \\
\hline 9 & $\begin{array}{l}\text { Keahlian } \\
(X 3.3)\end{array}$ & - & 1 & 44 & 55 & 3.54 & $\begin{array}{l}\text { Sangat } \\
\text { Setuju }\end{array}$ \\
\hline & & & & & 3.39 & $\begin{array}{l}\text { Sangat } \\
\text { Setuju }\end{array}$ \\
\hline & Rata-rata & & & & &
\end{tabular}

Sumber: Data Olahan Penelitian, 2020.

Penilaian indikator dengan nilai tertinggi terdapat pada konten menarik dengan nilai sebesar 3.59 dengan kategori sangat setuju. Indikator terendah terdapat pada komunikasi jujur dengan nilai sebesar 3.23 dengan kategori setuju, maka secara keseluruhan penilaian responden terhadap kredibilitas influencer adalah sangat setuju.

\section{Frekuensi Responden Terhadap Keputusan Berkunjung.}

Hasil persepsi mengenai keputusan berkunjung dapat dilihat dalam tabel di bawah ini.

Tabel 3. Frekuensi Keputusan Berkunjung

\begin{tabular}{|c|c|c|c|c|c|c|c|}
\hline \multirow{2}{*}{ No } & \multirow{2}{*}{ Pernyataan } & \multicolumn{4}{|c|}{ Frekuensi Penilaian } & \multirow{2}{*}{$\begin{array}{c}\text { Rata- } \\
\text { rata }\end{array}$} & \multirow{2}{*}{ Kategori } \\
\hline & & STS & TS & $\mathbf{S}$ & SS & & \\
\hline 1 & $\begin{array}{l}\text { Pengenalan } \\
\text { Masalah } \\
\text { (Y1.1) }\end{array}$ & 2 & 3 & 49 & 46 & 3.39 & $\begin{array}{l}\text { Sangat } \\
\text { Setuju }\end{array}$ \\
\hline 2 & $\begin{array}{l}\text { Pencarian } \\
\text { Informasi } \\
\text { (Y1.2) }\end{array}$ & 3 & 13 & 36 & 48 & 3.29 & $\begin{array}{l}\text { Sangat } \\
\text { Setuju }\end{array}$ \\
\hline 3 & $\begin{array}{l}\text { Evaluasi } \\
\text { Alternatif } \\
\text { (Y1.3) }\end{array}$ & - & 3 & 42 & 55 & 3.52 & $\begin{array}{l}\text { Sangat } \\
\text { Setuju }\end{array}$ \\
\hline 4 & $\begin{array}{l}\text { Keputusan } \\
\text { Berkunjung } \\
\text { (Y1.4) }\end{array}$ & 2 & 7 & 54 & 37 & 3.26 & $\begin{array}{l}\text { Sangat } \\
\text { Setuju }\end{array}$ \\
\hline 5 & $\begin{array}{l}\text { Ekspektasi } \\
\text { (Y1.5) }\end{array}$ & - & 2 & 52 & 46 & 3.44 & $\begin{array}{l}\text { Sangat } \\
\text { Setuju }\end{array}$ \\
\hline 6 & $\begin{array}{l}\text { Berkunjung } \\
\text { kembali } \\
\text { (Y1.6) }\end{array}$ & - & - & 31 & 69 & 3.69 & $\begin{array}{l}\text { Sangat } \\
\text { Setuju }\end{array}$ \\
\hline & & ata-rat: & & & & 3.43 & $\begin{array}{l}\text { Sangat } \\
\text { Setuju }\end{array}$ \\
\hline
\end{tabular}

Sumber: Data Olahan Penelitian, 2020

Berdasarkan data yang tertera, diketahui penilaian indikator dengan nilai tertinggi pada berkunjung kembali dengan nilai sebesar 3.69 dengan kategori sangat setuju. Indikator terendah terdapat pada keputusan berkunjung dengan nilai sebesar 3.26 dengan kategori setuju, maka secara keseluruhan penilaian responden 
terhadap keputusan berkunjung ke Labuan Bajo adalah sangat setuju.

\section{Uji Validitas}

Uji validitas dilakukan untuk melihat kesesuaiam penelitian dengan kondisi yang ada di lapangan. Berikut hasil uji validitas yang dapat dilihat pada tabel di bawah ini.

Tabel 4. Uji Validitas

\begin{tabular}{llc}
\hline \multicolumn{1}{c}{ Indikator } & Koefisien Korelasi & Keterangan \\
\hline Daya Tarik (X1) & & \\
X1.1 & 0.508 & Valid \\
X1.2 & 0.463 & Valid \\
X1.3 & 0.514 & Valid \\
\hline Kepercayaan & & \\
(X2) & & \\
X2.1 & 0.721 & Valid \\
X2.2 & 0.447 & Valid \\
X2.3 & 0.679 & Valid \\
\hline Keahlian (X3) & & \\
X3.1 & 0.758 & Valid \\
X3.2 & 0.719 & Valid \\
X3.3 & 0.603 & Valid \\
\hline Keputusan & & \\
Berkunjung (Y) & & \\
Y1.1 & 0.742 & Valid \\
Y1.2 & 0.739 & Valid \\
Y1.3 & 0.566 & Valid \\
Y1.4 & 0.699 & Valid \\
Y1.5 & 0.668 & Valid \\
Y1.6 & 0.445 & Valid \\
\hline Sumber: Data & 019 Pan Penelitian
\end{tabular}

Sumber: Data Olahan Penelitian, 2020

Berdasarkan ouput data, semua kuesioner yang diuji dinyatakan valid, yang mana nilainya berada di atas nilai standar yaitu 0,3 .

\section{Uji Reliabilitas}

Suatu variabel dinyatakan reliabel jika nilai alpha diatas 0,6. Adapun uji reliabilitas dapat dilihat pada tabel berikut ini.

Tabel 5. Uji Reliabilitas

\begin{tabular}{c|c}
\hline \multicolumn{2}{c}{ Reliability Statistics } \\
\hline Cronbach's Alpha & N of Items \\
\hline .887 & 15 \\
\hline
\end{tabular}

Sumber: Data Olahan Penelitian, 2020

Hasil nilai alpha menunjukkan angka 0.887 , maka dapat dikatakan bahwa instrumen dalam penelitian ini seluruhnya realibel, dengan nilai alpha melebihi standar minimal 0,600.

\section{Uji Normalitas}

Uji normalitas dilakukan untuk mengetahui apakah data berdistribusi normal atau tidak. Syarat uji statistik Kolmogorov-
Smirnov Test adalah residual berdistribusi normal jika nilai signifikansi > 0,05 (Ghozali, 2011). Berikut ini adalah hasil uji normalitas.

Tabel 6. Uji Normalitas

\begin{tabular}{|c|c|c|}
\hline \multicolumn{3}{|c|}{ One-Sample Kolmogorov-Smirnov Test } \\
\hline & & $\begin{array}{c}\text { Unstandardi } \\
\text { zed } \\
\text { Residual }\end{array}$ \\
\hline \multicolumn{2}{|l|}{$\mathrm{N}$} & 100 \\
\hline \multirow{2}{*}{$\begin{array}{l}\text { Normal } \\
\text { Parameters }{ }^{\mathrm{a}, \mathrm{b}}\end{array}$} & Mean & .0000000 \\
\hline & Std. Deviation & 1.64363370 \\
\hline \multirow{3}{*}{$\begin{array}{l}\text { Most Extreme } \\
\text { Differences }\end{array}$} & Absolute & .086 \\
\hline & Positive & .043 \\
\hline & Negative & -.086 \\
\hline \multicolumn{2}{|l|}{ Test Statistic } & .086 \\
\hline \multicolumn{2}{|c|}{ Asymp. Sig. (2-tailed) } & $.064^{\mathrm{c}}$ \\
\hline \multicolumn{3}{|c|}{ a. Test distribution is Normal. } \\
\hline \multicolumn{3}{|c|}{ b. Calculated from data. } \\
\hline
\end{tabular}

Sumber: Data Olahan Penelitian, 2020

Diketahui nilai signifikan adalah $0.064>0.05$, maka variabel-variabel yang berada dalam penelitian ini seluruhnya bersifat normal.

\section{Uji Multikolinearitas}

Uji multikolinieritas bertujuan untuk menguji model regresi memiliki korelasi antar variabel bebas atau tidak. Untuk menguji multikolinieritas, dilakukan dengan syarat nilai VIF masing-masing variabel memiliki nilai < 10, sehingga data dapat dinyatakan bebas dari gejala multikolinieritas (Ghozali, 2011).

Tabel 7. Uji Multikolinearitas

\begin{tabular}{lcc}
\hline & \multicolumn{2}{c}{ Collinearity Statistic } \\
\hline \multicolumn{1}{c}{ Variabel } & Tolerance & VIF \\
\hline Daya Tarik & 0.770 & 1.299 \\
Kepercayaan & 0.531 & 1.885 \\
Keahlian & 0.536 & 1.866
\end{tabular}

Sumber: Data Olahan Penelitian, 2020

Nilai VIF untuk Daya Tarik, Kepercayaan dan Keahlian masing-masing sebesar 1.299, 1.885 dan 1.866. Adapun nilai Tolerance Daya Tarik, Kepercayaan dan Keahlian masing-masing adalah 0.770, 0.531 dan 0.536. Berdasarkan hasil yang ada, maka disimpulkan tidak terjadi gejala multikolinearitas.

\section{Uji Heterokedastisitas}

Uji heterokedastisitas dilakukan untuk menguji ketidaksamaan variance dalam model regresi dari residual ke yang lainnya. Pengujian menggunakan Grafik Plot antara nilai ZPRED dengan SRESID. Tidak terjadi heteroskedastisitas apabila tidak ada pola yang 
pasti atau jelas dan titik-titik tersebar di atas dan di bawah angka 0 pada sumbu Y.

Gambar 2. Grafik Plot Uji Heterokedastisitas

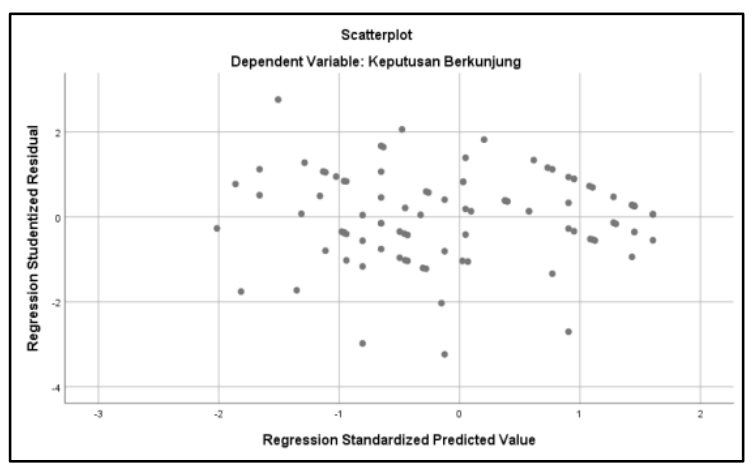

Sumber: Data Olahan Penelitian, 2020

Pada grafik di atas, diketahui tidak ada pola jelas yang terbentuk dan titik-titik tersebar di atas dan di bawah angka 0 pada sumbu $Y$, sehingga tidak ditemukan gejala heteroskedastisitas pada model regresi ini.

\section{Pengaruh Secara Parsial Kredibilitas Influencer di Media Sosial terhadap Keputusan Berkunjung.}

Tabel 8. Hasil Analisis Uji t

\begin{tabular}{lcc}
\hline \multicolumn{1}{c}{ Variabel } & t-hitung & Sig \\
\hline Daya Tarik & 2.052 & 0.043 \\
Kepercayaan & 2.012 & 0.047 \\
Keahlian & 6.590 & 0.000 \\
& & \\
\hline
\end{tabular}

Sumber: Data Olahan Penelitian, 2020

Berikut merupakan pembahasan setiap variabel secara parsial yaitu sebagai berikut:

1. Daya Tarik (Attractiveness)

Nilai t hitung adalah 2.052 dan nilai signifikan untuk pengaruh daya tarik $\left(\mathrm{X}_{1}\right)$ terhadap keputusan berkunjung (Y) adalah $0.043<0.05$. Maka, hipotesis pertama diterima, dimana terdapat pengaruh positif antara daya tarik dengan keputusan berkunjung. Dalam statistik, dinyatakan bahwa semakin positif daya tarik influencer, maka semakin tinggi keputusan wisatawan milenial untuk melakukan kunjungan ke Labuan Bajo. Menurut Glover (2009), kredibilitas influencer akan menarik perhatian audience, dalam hal ini merupakan pengikut dari influencer. Indikator yang digunakan dalam menilai daya tarik influencer ada 3 (tiga) yaitu meliputi tingkat menarik postingan, tingkat kesamaan minat berwisata ke Labuan Bajo dan tingkat perform (penampilan) influencer di Instagram. Hasil penelitian sesuai dengan penelitian terdahulu dari Permatasari (2009) dan Hastuti (2019), dimana terdapat pengaruh yang positif dan signifikan antara daya tarik dan keputusan pembelian. Namun, berbeda dengan penelitian Hidayat (2011), dimensi daya tarik tidak berpengaruh terhadap keputusan pembelian.

2. Kepercayaan (Trustworthiness)

Nilai $\mathrm{t}$ hitung adalah 2.012 dan nilai signifikan untuk pengaruh kepercayaan $\left(\mathrm{X}_{2}\right)$ terhadap keputusan berkunjung (Y) adalah $0.047<0.05$. Maka, hipotesis kedua diterima, dimana terdapat pengaruh positif antara kepercayaan dengan keputusan berkunjung. Dalam statistik, dinyatakan bahwa semakin positif kepercayaan influencer, maka semakin tinggi keputusan wisatawan milenial untuk berkunjung ke Labuan Bajo. Indikator yang digunakan dalam menilai kepercayaan influencer ada 3 (tiga) yaitu mengenai kepercayaan dalam membagikan informasi yang akurat, kepercayaan memberikan penilaian secara objektif dan meliputi kepercayaan dalam berkomunikasi jujur di media sosial Instagram. Hasil penelitian sesuai dengan penelitian terdahulu oleh Hidayat (2011) dan Hastuti (2019), dimana dimensi kepercayaan berpengaruh positif dan signifikan dengan keputusan pembelian. Selain itu, pada penelitian Permatasari (2009) juga ditemukan hasil yang serupa.

3. Keahlian (Expertise)

Nilai t hitung adalah 6.590 dan nilai signifikan untuk pengaruh keahlian $\left(\mathrm{X}_{3}\right)$ terhadap keputusan berkunjung (Y) adalah $0.000<0.05$. Maka, hipotesis ketiga diterima, dimana terdapat pengaruh positif antara keahlian dengan keputusan berkunjung. Indikator yang digunakan dalam menilai keahlian influencer ada 3 (tiga) yaitu meliputi tingkat pengetahuan influencer tentang Labuan Bajo, tingkat pengalaman influencer dengan daya tarik wisata Labuan Bajo dan mengenai keahlian influencer dalam mengolah konten postingan di media sosial Instagram. Menurut Shimp (2003), keahlian sendiri mengacu pada pengetahuan, pengalaman, atau keahlian yang dimiliki oleh seorang endorser yang dihubungkan oleh merek yang didukung, yang dalam hal ini 
merupakan Labuan Bajo. Hasil penelitian sesuai dengan penelitian terdahulu dari Permatasari (2009) dan Hidayat (2011), yang menyatakan bahwa terdapat pengaruh yang positif dan siginfikan antara dimensi keahlian dengan keputusan pembelian. Lebih lanjut dalam penelitian Khurri (2020), ditemukan hasil yang sama bahwa terdapat pengaruh antara keahlian dengan keputusan pembelian.

\section{Pengaruh Secara Simultan Kredibilitas Influencer di Media Sosial terhadap Keputusan Berkunjung.}

Tabel 9. Hasil Analisis Uji F

\begin{tabular}{llrrc}
\hline & Model & Mean Square & F & Sig \\
\hline 1 & Regression & 140.246 & 50340 & 0.000 \\
& Residual & 2.786 & & \\
& Total & & &
\end{tabular}

Sumber: Data Olahan Penelitian, 2020

Dimensi kredibilitas influencer dalam penelitian ini mencakup tiga variabel, yaitu daya tarik, kepercayaan dan keahlian. Ketiga variabel ini memiliki pengaruh yang positif dan signifikan terhadap keputusan wisatawan milenial berkunjung ke Labuan Bajo. Hasil penelitian menunjukkan nilai signifikan $0.000<$ 0.05. Sedangkan, nilai f-hitung diperoleh angka 50.340. Berdasarkan hal tersebut, dapat disimpulkan bahwa dimensi kredibilitas influencer berpengaruh secara simultan terhadap keputusan berkunjung wisatawan milenial ke Labuan Bajo. Penelitian ini sejalan dengan penelitian yang dilakukan oleh (Sugiharto \& Ramadhana, 2018). Selain itu, hasil penelitian ini juga diperkuat dengan penelitian sebelumnya dari Khurri (2020).

\section{Koefisien Korelasi}

Koefisien korelasi digunakan untuk mengetahui kuat dan lemahnya tingkat atau derajat hubungan koefision korelasi antara dimensi kredibilitas influencer dengan keputusan berkunjung, yang disajikan dalam tabel berikut.

Tabel 10. Koefisien Korelasi

Model Summary ${ }^{\mathrm{b}}$

\begin{tabular}{c|c|c|c|c}
\hline Model & $\mathrm{R}$ & $\begin{array}{c}\mathrm{R} \\
\text { Square }\end{array}$ & $\begin{array}{c}\text { Adjusted } \\
\text { R Square }\end{array}$ & $\begin{array}{c}\text { Std. } \\
\text { Error of }\end{array}$ \\
\hline
\end{tabular}

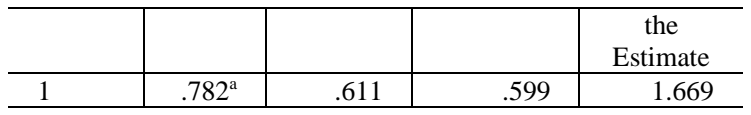

a. Predictors: (Constant), Keahlian, Daya Tarik,

Kepercayaan

b. Dependent Variable: Keputusan Berkunjung

Sumber: Data Olahan Penelitian, 2020

Data di atas menunjukan bahwa besarnya koefisien korelasi adalah $(\mathrm{R}=0.782)$, yang berarti dimensi kredibilitas influencer mempunyai hubungan yang sangat baik dengan variabel keputusan berkunjung.

\section{Koefisien Determinasi}

Analisis koefisien determinasi dilakukan untuk mengetahui besar nilai variasi atau pengaruh yang diberikan dimensi kredibilitas influencer dengan keputusan wisatawan milenial untuk berkunjung ke Labuan Bajo, yang dapat dilihat pada tabel di bawah ini.

Tabel 11. Koefisien Determinasi

\begin{tabular}{|c|c|c|c|c|}
\hline \multicolumn{5}{|c|}{ Model Summary $^{\text {b }}$} \\
\hline Model & $\mathrm{R}$ & $\begin{array}{c}\mathrm{R} \\
\text { Square }\end{array}$ & $\begin{array}{l}\text { Adjusted } \\
\text { R Square }\end{array}$ & $\begin{array}{c}\text { Std. } \\
\text { Error of } \\
\text { the } \\
\text { Estimate }\end{array}$ \\
\hline 1 & $.782^{\mathrm{a}}$ & .611 & .599 & 1.669 \\
\hline \multicolumn{5}{|c|}{$\begin{array}{l}\text { a. Predictors: (Constant), Keahlian, Daya Tarik, } \\
\text { Kepercayaan }\end{array}$} \\
\hline
\end{tabular}

Sumber: Data Olahan Penelitian, 2020

Diketahui nilai $\mathrm{R}$ square 0.611 artinya bahwa dimensi kredibilitas influencer di media sosial Instagram memberikan pengaruh sebesar $61.1 \%$ terhadap keputusan berkunjung wisatawan milenial ke Labuan Bajo, sedangkan sisanya $39.9 \%$ merupakan variabel lain yang tidak diteliti oleh peneliti.

\section{SIMPULAN DAN SARAN Simpulan}

Berdasarkan 100 sampel yang telah dibagikan kepada 100 wisatawan milenial yang ke Labuan Bajo, didapati karakteristik berdasarkan usia, generasi milenial awal dengan rentang usia 20 - 29 tahun merupakan yang terbanyak sebesar $87 \%$, jenis kelamin perempuan mendominasi sebesar $63 \%$. Berdasarkan status pernikahan yaitu belum menikah sebesar $87 \%$. Berdasarkan daerah asal wisatawan sebesar $35 \%$ berasal dari provinsi Bali. Berdasarkan status pendidikan, didapati dengan tingkat pendidikan Sarjana sebesar 54\%. 
Berdasarkan profesi, didapati mahasiswa sebesar 35\%. Berdasarkan pendapatan per bulan, didapati pendapatan sebesar Rp. 2.500.000 - Rp.5.000.000 mendominasi sebesar $61 \%$. Berdasarkan akomodasi yang digunakan, didapati akomodasi hotel yang paling tertinggi sebesar $46 \%$. Berdasarkan tujuan berkunjung, didapati berlibur sebesar 92\%. Berdasarkan frekuensi kunjungan, dengan kunjungan pertama kali sebesar $77 \%$.

Pada penelitian ini, berdasarkan hasil ditemukan pengaruh variabel daya tarik, kepercayaan dan keahlian di media sosial instagram terhadap keputusan wisatawan milenial berkunjung ke Labuan Bajo. Secara parsial, semua dimensi kredibilitas influencer memiliki pengaruh positif dan signifikan dengan hasil sebagai berikut: nilai signifikan sebesar $0.043<0.05$, sedangkan t-hitung nilainya sebesar $2.052\left(\mathrm{X}_{1}\right.$ terhadap $\left.\mathrm{Y}\right)$; nilai signifikan sebesar $0.047<0.05$, sedangkan t-hitung nilainya sebesar $2.012\left(\mathrm{X}_{2}\right.$ terhadap $\left.\mathrm{Y}\right)$; nilai signifikan sebesar $0.000<0.05$, sedangkan thitung nilainya sebesar 6.590 ( $\mathrm{X}_{3}$ terhadap $\left.\mathrm{Y}\right)$.

Pada penelitian ini, berdasarkan hasil ditemukan pengaruh dimensi kredibilitas influencer secara simultan berpengaruh terhadap keputusan berkunjung dengan nilai signifikan $0.000<0.05$, sedangkan untuk f-hitung diperoleh nilai sebesar (50.340). Dari hasil tersebut, maka dapat disimpulkan bahwa secara simultan terdapat pengaruh antara dimensi kredibilitas influencer terhadap keputusan wisatawan milenial berkunjung ke Labuan Bajo.

\section{Saran}

Untuk influencer, berdasarkan hasil penelitian, pengaruh variabel daya tarik (X1), kepercayaan (X2) dan keahlian (X3) memiliki pengaruh terhadap keputusan berkunjung sebesar $61.1 \%$, oleh sebab itu, kredibilitas influencer kiranya dapat ditingkatkan lagi dengan cara membuat konten menarik seperti melakukan Q and A (Question and Answer) pada media sosial mengenai perjalanan wisata yang telah dilakukan, mengajak para audience atau followers berkolaborasi dalam memberikan penilaian atau review mengenai suatu perjalanan, sehingga penilaian (review) yang diberikan dapat bermanfaat bagi para pengikut (followers) yang ingin mengetahui suatu atraksi wisata.

Untuk pemerintah Labuan Bajo dalam mempromosikan destinasi wisata dan untuk mendukung program "10 Bali Baru” agar kiranya dapat melibatkan lebih banyak lagi influencer, khususnya influencer yang berfokus kepada perjalanan wisata agar dapat memberikan informasi mengenai perjalanan, berbagi konten informatif dan membuat video promosi destinasi wisata ke Labuan Bajo, sehingga kiranya dapat memberikan kontribusi untuk mencapai jumlah kunjungan wisata yang telah ditargetkan atau ditetapkan sebelumnya oleh pemerintah.

Untuk penelitian mendatang, penulis menyadari keterbatasan penelitian ini, perlu diakui bahwa ukuran sampel yang digunakan tergolong kecil. Oleh karena itu, hasil penelitian ini mungkin tidak mewakili pemikiran keseluruhan wisatawan milenial yang melakukan kunjungan wisata ke Labuan Bajo, kiranya untuk peneliti selanjutnya dapat memperluas ukuran sampel untuk mendapatkan gambaran yang lebih baik lagi. influencer yang diteliti juga kiranya dapat ditambahkan, agar gambaran mengenai influencer dapat lebih jelas. Selain itu, untuk penelitian yang akan datang agar dapat menambah variabel media sosial sehingga penelitian ini menjadi lebih baik dalam mengukur kredibilitas influencer di media sosial terhadap keputusan berkunjung wisatawan milenial. 


\section{Kepustakaan}

Badan Pusat Statistik [BPS]. 2019. Statistik Kunjungan Wisatawan ke Labuan Bajo. Badan Pusat Statistik Manggarai Barat.

Franedya, R. 2019. Survei: Pengguna Internet di RI Tembus 171,17 Juta Jiwa. (https://www.cnbcindonesia.com, diakses 2 Januari 2020).

Ghozali. 2011. Aplikasi analisis multivariate dengan program SPSS. Penerbit: Universitas Diponegoro.

Glover. 2009. Celebrity Endorsement in Tourism Advertising: Effects on Destination Image. Journal of Hospitality and Tourism Management.

Hanifah, Regina Dewi. 2019. The Influence of Instagram Travel Influencer on Visiting Decision of Tourist Destinations for Generation $Y$. Jakarta: Universitas Bunda Mulia.

Hastuti, S. 2019. Pengaruh kredibilitas celebrity endorser pada iklan Pond's terhadap keputusan pembelian konsumen (studi pada mahasiswa pengguna produk Pond's di Universitas Negeri Malang). Malang: Universitas Negeri Malang.

Heruwati, E., \& KHASANAH, I. 2010. Analisis Pengaruh Daya Tarik, Kredibilitas, Dan Keahlian Celebrity Endorser Terhadap Keputusan Pembelian Sepeda Motor Yamaha Mio (Studi pada konsumen PT Harpindo Jaya Jl. Dr. Cipto No. 61 Semarang). Semarang: Universitas Diponegoro.

Hidayat, 2011. Analisis Pengaruh Daya Tarik, Kredibilitas dan Keahlian Celebrity Endorser Terhadap Keputusan Pembelian Sepeda Motor Yamaha Mio. Jakarta: Universitas Islam Negeri Syarif Hidayatullah.

Hariyanti, T. N \& Wirapjaja, A. 2018. Pengaruh Influencer Marketing Sebagai Strategi Pemasaran Digital Modern (Sebuah Studi Literatur). Jurnal EKSEKUTIF (Vol. 5, No. 1 Juni 2018: 133-146).

Khurri. 2020. Pengaruh Daya Tarik, Kepercayaan, dan Keahlian Terhadap Keputusan Pembelian. Malang: Universitas Islam Malang.

Ohanian, R. 1990. Construction and validation of a scale to measure celebrity endorsers' perceived expertise, trustworthiness, and attractiveness. Journal of advertising, 19(3), 39-52.

Permatasari, Berlintina. 2019. Pengaruh Daya Tarik, Kepercayaan, dan Keahlian Celebrity Endorser Terhadap Keputusan Pembelian. Jurnal TECHNOBIZ Vol. 3, No. 6, 2019 (3136). Bandar Lampung: Universitas Teknokrat Indonesia.

Prodjo, Wahyu Adityo. 2017. 10 Destinasi "Bali Baru", 4 Destinasi Jadi Prioritas. (https://travel.kompas.com/read/2017/1 1/18/122700027/10-destinasi-bali-baru4-destinasi-jadi-prioritas, diakses 5 Januari 2020).

Shimp, T. A. 2007. Advertising Promotion and Supplement Aspect of Integrated Marketing Communicatio. ; Alih Bahasa: Periklanan Promosi dan Aspek Tambahan Komunikasi Pemasaran Terpadu.

Sugiharto \& Ramadhana, 2018. Pengaruh Kredibilitas Influencer Terhadap Sikap Pada Merek (Studi Pada Mahasiswa Fakultas Komunikasi Dan Bisnis Universitas Telkom). Jurnal Ilmu Politik dan Komunikasi Volume VIII No. 2 / Desember 2018. 